Анализ динамики климатических сумм температур, накопленных за зимний сезон последних шести десятилетий, показал, что второе десятилетие (1951-1960 гг.) было самым холодным, в последующие десятилетия, хотя и отмечались отдельные холодные зимы, но наблюдалась устойчивая тенденция потепления зим. Средняя сумма температур за зимний период по десятилетиям: 19411950, 1951-1960, 1961-1970, 1971-1980, 19811990, 1991-2000 гг. составила соответственно $-1174,-1214,-1040,-932,-875,-907^{\circ} \mathrm{C}$.

Существенные изменения климата области в сторону потепления особенно заметны в холодную часть года. С 1980-х гг. начинают преобладать положительные аномалии температуры во все зимние месяцы, в отдельных случаях аномалия температуры достигала весьма значительных величин более $8^{\circ} \mathrm{C}$.

Столь резкое потепление климата на юге Русской равнины не является случайным, а представляет собой часть глобального потепления, особенно усилившегося в 1980-х годах.

Тщательный анализ ежедневного метеорологического материала по станциям Саратовской области показал, что потепление и увеличение осадков в зимний период создают более благоприятные условия для зимующих культур, а повышение температуры воздуха в мае в последние десятилетия способствует усилению засушливых явлений в начале лета, что неблагоприятно сказывается на возделывании яровых зерновых культур. Увеличение посевных площадей под озимые культуры будет способствовать более рациональному использованию естественных природных ресурсов региона.

\section{Библиографический список}

1. Пряхина С.И., Скляров Ю.А., Заварзин А.И. Природные ресурсы Нижнего Поволжья и степень их использования зерновыми культурами. Саратов, 2001. 66 с.

2. Пряхина С.И. Климатическая характеристика сезонов. Климат Саратова. Л., 1987. С.91-102.

\title{
ВЫДЕЛЕНИЕ ПОЛУСУТОЧНОГО ПЕРИОДА С МАКСИМАЛЬНЫМ ВКЛАДОМ ДНЕВНОЙ ТЕРМИЧЕСКОЙ КОНВЕКЦИИ В ЛЕТНЕЕ ОСАДКООБРАЗОВАНИЕ В ПОВОЛЖЬЕ
}

\section{О.Б. Цой, Д.Н. Кравченко}

Саратовский государственный университет, кафедра метеорологии и климатологии E-mail: TsoyOB@list.ru

В статье приводятся результаты определения полусуточного периода с максимальным вкладом дневной термической конвекции в летнее осадкообразование. Такой дневной период определен для Пензенской и Саратовской областей, как 10-22 ч м.д.в. Оценен вклад дневной термической конвекции в усиление осадкообразования в данном регионе. Дневной нагрев подстилающей поверхности обусловливает увеличение сумм осадков в среднем не менее чем на треть.

Allocation of a Half-Daily Period with the Maximal Contribution of a Day Thermal Convection in Summer Rain Genesis in the Volga-Region

\section{O.B. Tsoi, D.N. Kravchenko}

Results of definition of half-daily period with the maximal contribution of a day thermal convection in summer rain genesis are considered. This day period is determined for Penza and Saratov areas as $10-22 \mathrm{~h}$. msk. The contribution of day thermal convection in strengthening of rain genesis of these regions is estimated. The diurnal heating of a underlying surface causes increase of the precipitations sum for not less than one third in average.

Существующее в гидрометеорологической практике деление суток на полусуточные интервалы («день» и «ночь»), как правило, формально и для разных целей различно. Например, двухразовое (за «день» и за «ночь») измерение осадков в течение суток на гидрологических постах осуществляется в стандартные сроки, ближайшие к 8 ч и 20 ч по декретному времени данного пояса, а на агрометеопостах - в 6 ч и в 18 ч московского 
декретного времени. Астрономическое деление суток на «день» и «ночь» обусловливает их различную продолжительность в зависимости от изменяющегося периода между восходом и заходом солнца, что неудобно для сравнения измеренных величин, например, дневных и ночных осадков. В данной работе представлены результаты попыток нового полусуточного деления на «день» и «ночь» применительно к целям исследования внутрисуточной изменчивости жидких осадков теплого периода в Поволжье.

Принципиальной разницей между дневными и ночными процессами осадкообразования в теплый период является существенное влияние на осадкообразование днем фактора термической конвекции, отсутствующего ночью. Развитие восходящих воздушных потоков, обусловленных дневной термической конвекцией, способствует интенсификации процесса внутримассового осадкообразования, что при определенных условиях температурной и влажностной стратификации должно приводить и к увеличению дневных сумм осадков относительно ночных. Конечно, циркуляционный фактор осадкообразования (фронтальные осадки) на данной территории является наиболее мощным, однако при достаточно большом периоде исследования повторяемость фронтальных ситуаций в течение суток становится равномерной, и разность между дневными и ночными суммами осадков должна главным образом определяться фактором термической конвекции.

Для исследования были использованы данные плювиографических наблюдений опорного плювиографического поста Пензенской базы Центральной аэрологической обсерватории (ЦАО) - п. Б. Елань (центр Пензенской обл.) за теплые периоды (май август) 1987-1992 гг. и плювиопоста экспедиции Саратовского госуниверситета п. Н. Воронок (центр Саратовской обл.) за июнь - июль 1977-1986 гг. Плювиографические наблюдения позволяют определять с достаточной точностью суммы осадков, выпавших в данном месте практически за любой интервал времени. В работе рассчитывались полусуточные суммы осадков ( $Q$ мм) за 12-часовые периоды с плавающими (на 1 ч) временными границами (например, 6-18 ч,
7-19 ч, 8-20 ч и т.д.). Все данные приводились к срокам московского декретного времени. Для каждого нового варианта полусуточного разбиения рассчитывалось отношение

$$
N=Q_{\text {д }} / Q_{\text {н }},
$$

где $Q_{\text {д }}$ сумма всех дневных осадков исследуемого периода (день - наиболее близкий к астрономическому «дню» 12-часовой интервал из двух полученных при каждом полусуточном разбиении); $Q_{\text {н }}$ сумма ночных осадков того же периода (ночь - следующий за днем 12-часовой интервал).

Результаты полученных расчетов, по данным постов Б.Елани и Н.Воронка, приведены на рис. 1 и 2. Для удобства представления на рисунках изображены только участки расчетных кривых с максимальными значениями $N$.

Несмотря на различные временные периоды анализируемых данных, для обоих постов получены кривые (рис. 1, 2) схожего характера. Для этих постов возможно выделение одинаковых полусуток с максимальным превышением дневных осадков над ночными. Максимальные значения $N$, равные 2,24 (Н. Воронок) и 2,25 (Б. Елань), относятся к полусуточным временным границам 10 ч / 22 ч московского декретного времени. На рис. 1 максимальное значение $N=2,25$ получено также и для полусуточных границ $11 / 23$ ч м.д.в. Однако, учитывая слабую левостороннюю асимметрию вершины, в качестве «дневных» полусуток можно принять такой же период, как и для Н.Воронка 10/22 ч. Данный результат совпадает с выделенным ранее О.Б.Цоем (по другому объему данных) дневным периодом для Пензенской области [1].

Заметен более сглаженный характер правого плеча кривой на рис.2, по сравнению с четко выраженной вершиной на рис.1. Рассчитанные $N$ на рис. 2 превышают значения 2,0 для многих полусуточных интервалов, в том числе и относительно «поздних»$11 / 23,12 / 24,13 / 01$ ч. Это свидетельствует о большой «растянутости» влияния термического нагрева на осадкообразование на посту Н.Воронок в сторону вечерних сроков. Данный пост был расположен на острове, в пойме Волгоградского водохранилища, то есть среди обширного водного пространства. 


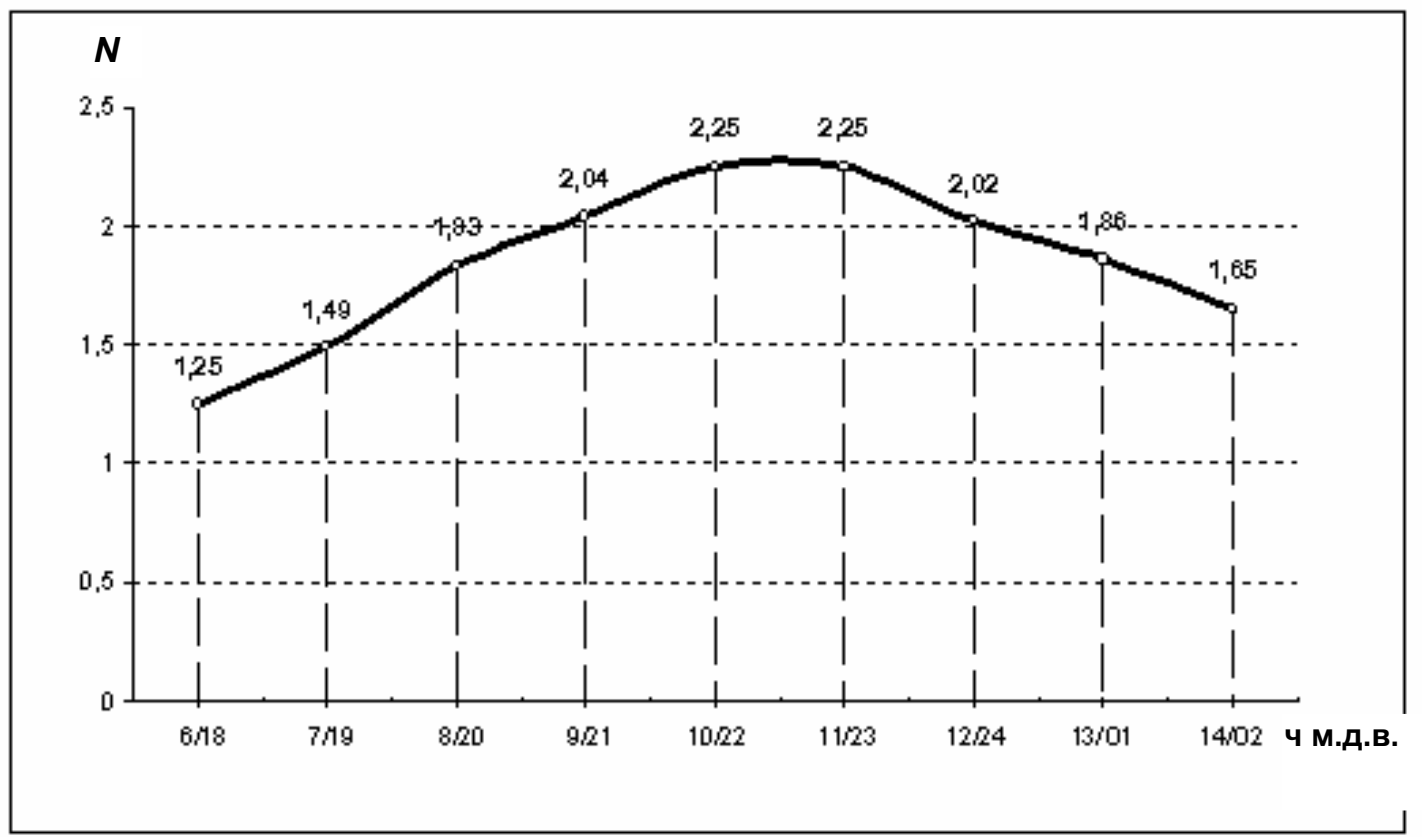

Рис.1. Изменение параметра $N$ при различных полусуточных периодах в мае-августе 1987-1992 гг. (Б.Елань, Пензенская область)

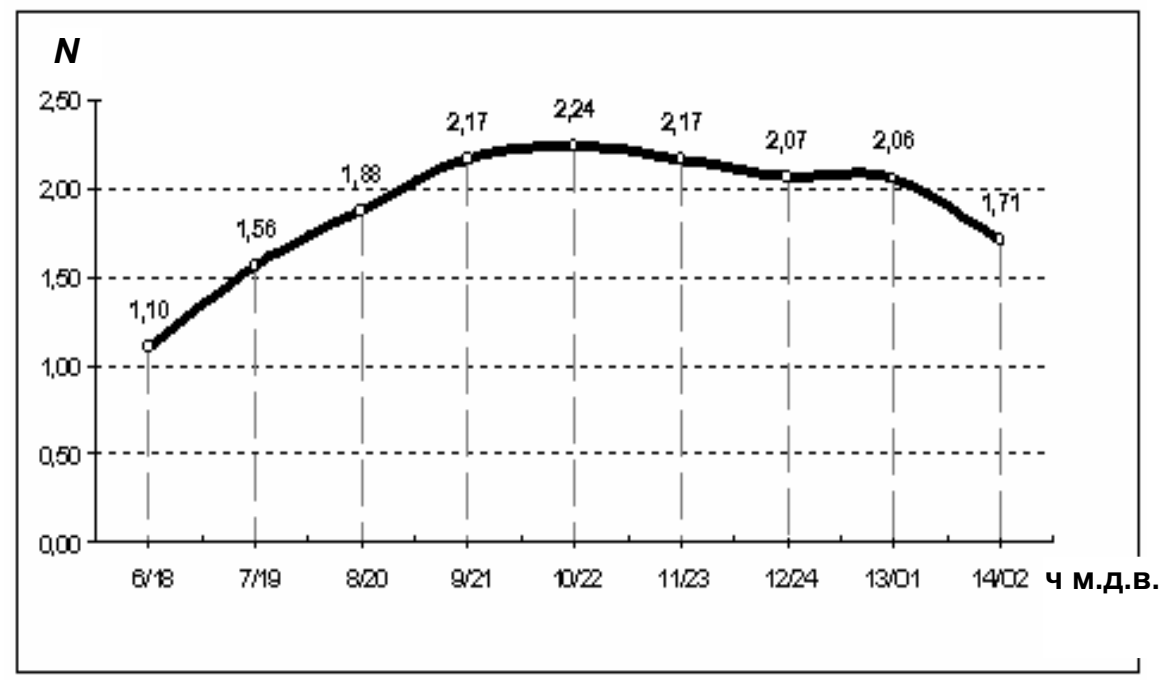

Рис.2. Изменение параметра $N$ при различных полусуточных периодах в июне-июле 1977-1986 гг. (Н.Воронок, Саратовская область)

Высокая теплоемкость воды приводит к сглаживанию суточного хода температуры водной поверхности и смещению максимальной температуры этой поверхности на более поздние сроки (относительно суши) [2], что соответственно может «растягивать» воздействие дневного нагрева подстилающей поверхности на термическую конвекцию и осадкообразование в данном месте.

По полученным значениям $N$ можно оценить вклад дневной термической конвекции в летнее осадкообразование в Пензен- ской и Саратовской областях. Термическая конвекция в дневные полусутки, с 10 до 22 ч м.д.в., способствует удвоению относительно «ночи» суммы выпадающих в данном регионе осадков, то есть суточные суммы осадков за счет данного фактора в среднем увеличиваются чуть более чем на треть. Конечно, данное увеличение осадков может происходить как за счет усиления внутримассовой осадкообразующей облачности, так и за счет интенсификации осадкообразования во фронтальной облачности днем [1]. 
Проведение помесячного анализа изменения параметра $N$ при разных полусуточных границах на используемом объеме данных приводит к значительному ослаблению надежности результатов вследствие усиления влияния циркуляционного фактора на внутрисуточное распределение осадков. Тем не менее предварительный анализ помесячного хода параметра $N$ для п. Б.Елань показал, что полученный на рис.1 вид кривых формируется в основном за счет июнь-июльских значений $N$, а май и август могут существенно отличаться от средних месяцев периода невозможностью четкого выделения одного максимума в ходе параметра $N$. Для проведения надежного помесячного анализа необходимо использовать больший объем данных.
Таким образом, проведенное исследование позволяет выделить одинаковый полусуточный период («день» $-10-22$ ч м.д.в.) с максимальным вкладом дневной термической конвекции в осадкообразование в двух соседних областях Поволжья, а также оценить величину этого вклада. Термическая конвекция летом приводит к увеличению общей суточной суммы осадков в среднем не менее чем на треть.

\section{Библиографический список}

1. Цой О.Б. Некоторые результаты исследования структуры летних осадков над Средним Поволжьем // Метеорология и гидрология. 1998. Вып.3. С 13-28.

2. Волков С.А. Микроклиматы северной части Волгоградского водохранилища. Дис. ... канд. геол. наук. Саратов, 1974. $148 \mathrm{c}$. 